\title{
Disclosure and Consent to Medical Research Participation
}

\author{
Danielle Bromwich* \\ Department of Philosophy, University of Massachusetts Boston \\ daniellebromwich@gmail.com \\ Joseph Millum** \\ Clinical Center Department of Bioethics/Fogarty International Center \\ National Institutes of Health \\ millumj@cc.nih.gov
}

\begin{abstract}
Most regulations and guidelines require that potential research participants be told a great deal of information during the consent process. Many of these documents, and most of the scholars who consider the consent process, assume that all this information must be disclosed because it must all be understood. However, a wide range of studies surveying apparently competent participants in clinical trials around the world show that many do not understand key aspects of what they have been told. The standard view of the conditions for valid consent therefore implies that these people have failed to give valid consent to research participation. In this paper we argue that the standard view is false. The primary function of the requirement that researchers disclose information about a study is the avoidance of illegitimate control over someone's consent decision, which is a form of fraud. We derive the content and manner of appropriate disclosure by analysing the ways in which the manipulation of information can invalidate consent. Our analysis shows that the informational requirements for valid consent are conceptually distinct and thus unlikely to have identical contents. This implies that consent can be valid when not everything that ought to be disclosed by the person asking for consent is understood by the person who proffers it.
\end{abstract}

* Danielle Bromwich is an Assistant Professor in Philosophy at the University of Massachusetts, Boston, and formerly a post-doctoral fellow at the Department of Bioethics in the Clinical Center at the National Institutes of Health. She works on moral motivation and consent to medical research participation.

** Joseph Millum, PhD, serves as a liaison between the National Institutes of Health (NIH) Clinical Center Department of Bioethics and the Division of International Science Policy, Planning, and Evaluation at the Fogarty International Center, where he provides ethics consultation and educational support. His current research focuses on the rights and responsibilities of parents, global justice, health policy, and ethical issues in international research. 


\section{Keywords}

consent; informed consent; autonomy rights; disclosure; understanding; fraud; medical research; bioethics

\section{Introduction}

Jewish Chronic Disease Hospital. ${ }^{1}$ In 1963 , three medical researchers at the Jewish Chronic Disease Hospital in Brooklyn, New York, injected live cancer cells into 22 chronically ill patients. Their experiment was designed to find out how quickly a debilitated body would reject foreign cells. The physician who was responsible for obtaining consent for most of these procedures told his patients that "an injection of the cell suspension was planned as a skin test for immunity or resistance" 2 and that within a few days a lump would form at the injection site which would disappear over a few weeks. The patients were not told that the injection contained live cancer cells or that the procedure was experimental. The researchers withheld the precise nature of the cells because they were concerned about "the phobia and ignorance that surrounds the word cancer," ${ }^{3}$ and they considered the cancerous nature of the cells immaterial since they would cause a defense reaction just by virtue of being foreign. Telling already debilitated patients that the injections contained live cancer cells would only serve to "stir up ... unnecessary anxieties, disturbances or phobias."

Lazy Participant. On her way to work, Dawn sees an advertisement for a study at the Well-being Hospital's Asthma Research Center. The researchers are looking for asthmatics to participate in a study of genetic factors that influence the therapeutic response to a common asthma medication for exercise induced asthma. The study only involves a few hospital visits over a one-month period, yet it comes with a free medical check-up, free asthma medications, and up to $\$ 260$ in compensation. Dawn lives close to the hospital, and she knows it's a very reputable facility. Her mind made up, Dawn fills out an online form, and is contacted by the principal investigator, Dr Abrams, later that week. Dr Abrams sends her a consent form to read, and schedules a time to talk about the research and answer questions. Dawn glances over the consent form and notices that it is just as easy to read as the advertisement. But within two minutes she is bored of reading and returns to daytime television. She tells herself that reading the consent form is a waste of time, since she's already decided to participate in the study. However, she is a little ashamed of her laziness, so when they meet she doesn't tell Dr Abrams that she hasn't read the form; she just says, "It all seems straightforward to me. I only have one question: When do we start?" Dawn signs the consent form and is enrolled in the study.

1 This account is drawn from Jay Katz, with Alexander Morgan Capron and Eleanor Swift Glass, "The Jewish Chronic Disease Case," in Experimentation with Human Beings (New York: Russell Sage Foundation, 1972), 9-65.

2 Dr Deogracias C. Custodio quoted in Katz, Experimentation with Human Beings, 25

3 Dr Chester M. Southam quoted in ibid., 11.

4 Dr Deogracias B. Custodio quoted in ibid., 25. 
The importance of consent for human interactions-economic, medical, and personal-is undisputed. The requirement that valid consent be obtained protects us from unwanted interference, while the ability to grant it allows us to transform our moral relationship to others in ways that advance our interests and goals. Consent therefore allows autonomous agents control over their lives. Since we value having our valid tokens of consent recognized as such, and since proceeding without valid consent often involves a serious rights violation, it is vitally important to work out the conditions under which a token of consent is valid.

The ethics of consent has been extensively analyzed in contexts in which it plays an important role. For example, bioethicists have helpfully divided the consent process into five necessary and jointly sufficient elements: the person granting consent must have the capacity to give consent, relevant information about the act consented to must be disclosed to her, she must have sufficient understanding of the act, her decision must be voluntary, and she must provide some token indicating that consent has been given. ${ }^{5}$ In this paper we focus on the relationship between the informational requirements for valid consent, that is, the disclosure and understanding requirements.

Consent to medical research participation is a context in which an individual typically requires a significant amount of new information to be provided to her if she is to have a fair opportunity to control what happens to her. It is therefore a useful context to focus on in order to illuminate the informational requirements for consent in general. Most regulations and guidelines require that potential research participants be told a great deal of information, including the purpose of the research, the procedures involved, foreseeable risks and benefits, alternatives to participation, and assurance of their freedom to withdraw. ${ }^{6}$ Many of these documents, and

5 See Ruth R. Faden, Tom L. Beauchamp, and Nancy M. P. King, A History and Theory of Informed Consent (New York: Oxford University Press, 1986); Robert J. Levine, Ethics and Regulation of Clinical Research. 2nd ed. (Baltimore: Urban \& Schwarzenberg, 1986); and Tom L. Beauchamp and James F. Childress, Principles of Biomedical Ethics. $6^{\text {th }}$ ed. (New York: Oxford University Press, 2009).

${ }_{6}$ Nuremberg Military Tribunal, from U. S. $v$ Karl Brandt, et al., The Nuremberg Code, 1947; The National Commission for the Protection of Human Subjects of Biomedical and Behavioral Research. The Belmont Report: Ethical Principles and Guidelines for the Protection of Human Subjects of Research. (Washington, D. C.: Department of Health, Education and Welfare, 1979); The Council for International Organizations of Medical Sciences (CIOMS) in collaboration with the World Health Organization (WHO): The International Ethical Guidelines for Biomedical Research Involving Human Subjects. (Geneva, 2002); and World Medical Association, Declaration of Helsinki: Ethical Principles for Medical Research Involving Human Subjects. (Seoul: October 2008). 
most of the scholars who consider the consent process, assume that all this information must be disclosed because it must all be understood. ${ }^{7}$ This "standard view" therefore considers that the content of the understanding requirement (what potential participants must understand in order to give valid consent) is identical to the content of the disclosure requirement (what researchers must tell potential participants in order for consent to be valid). ${ }^{8}$ As Alexander M. Capron puts it: "[p]ainly, comprehension is essential for truly informed consent, for the act of disclosure would otherwise be pointless." ${ }^{9}$

According to the standard view, the tokens of consent given in Jewish Chronic Disease Hospital and Lazy Participant are invalid, since in both cases the research participants do not understand some information that they should have been told. Indeed, a wide range of studies surveying apparently competent participants in clinical trials around the world show that many do not understand key aspects of what they have been told. ${ }^{10}$

7 The two most cited international guidelines for ethical research involving human participants, the Declaration of Helsinki and CIOMS, require that prospective participants understand what has been disclosed to them. The Declaration of Helsinki states that "[a]fter ensuring that the potential subject has understood the information, the physician or another appropriately qualified individual must then seek the potential subject's freely-given informed consent, preferably in writing." (WMA, Helsinki, B24). CIOMS states that after disclosure "the investigator must then ensure that the prospective subject has adequately understood the information." (CIOMS, International Ethical Guidelines, Commentary on Guideline 4).

8 Three notable exceptions are Bernard Gert, Charles M. Culver, K. Danner Clouser, Bioethics: A Return to Fundamentals (New York: Oxford University Press, 1997), 151, who hold that the purpose of disclosure is to avoid deception, David Wendler in "Must Research Participants Understand Randomization?" American Journal of Bioethics 9 (2009): 3-8, argues that prospective participants do not need to understand randomization to give valid consent to enroll in a randomized controlled trial even though information about randomization should be disclosed to them, and Gopal Sreenivasan "Does Informed Consent to Research Require Comprehension?" Lancet 362 (2003): 2016-8, who writes that: "the point of disclosing information is to impart a certain grasp of the procedure or the protocol in question. An aspiration to produce adequate comprehension is therefore inseparable from the requirement of disclosure. It does not follow, however, that the success in producing comprehension is likewise required" (ibid., 2016). In this paper we explain why a version of this alternative view is correct and explore what that tells us about the nature and content of the disclosure requirement.

9 Alexander M. Capron, "Legal and Regulatory Standards of Informed Consent in Research," in E. Emanuel et al., eds, The Oxford Textbook of Clinical Research Ethics (New York: Oxford University Press, 2008), 625.

10 This variation remains constant across settings and research participant populations. For an overview of the empirical data on the quality of consent to research, see James H. Flory, David Wendler, Ezekiel E. Emanuel, "Empirical Issues in Informed Consent for 
For example, many research participants suffer from a "therapeutic misconception"- a tendency to confuse the purpose of procedures that are actually being carried out for research with procedures in personalized medical care that are being carried out for the benefit of the patient. ${ }^{11}$ The standard view therefore implies that many people fail to give valid consent to research participation, which would mean that many studies that were thought to be ethical were really not.

In this paper, we argue that the standard view is false. The regulations and guidelines are right to require researchers to disclose a great deal of information to potential participants. However, this is not because they must understand all this information, but because researchers risk invalidating consent through a form of fraud by withholding or misrepresenting information that is relevant to an enrollment decision. We argue that fraudulent disclosure can be avoided by just giving the person proffering consent a fair opportunity to understand the information that ought to be disclosed to her. This implies that it is possible for people to give valid consent to medical research participation without actually understanding all of the information that has rightly been disclosed. The correct diagnosis of what went wrong in Jewish Chronic Disease Hospital is therefore that people were fraudulently enrolled into research. However, our analysis implies that Dawn's consent in Lazy Participant may be perfectly valid, and studies that show poor participant understanding are not sufficient evidence to show that the clinical trials in question are unethical. We close with an analysis of how fraudulent disclosure can invalidate consent that allows us to derive conditions for what information must be disclosed and how. ${ }^{12}$

This analysis has important implications for the practice of obtaining consent to research participation. However, it also yields two general lessons regarding the informational requirements for consent: that the disclosure and understanding requirements are conceptually distinct, and that

Research," in E. Emanuel et al., eds, The Oxford Textbook of Clinical Research Ethics (New York: Oxford University Press, 2008).

${ }^{11}$ See ibid. For more information on the therapeutic misconception, see footnote 34.

12 The view we develop in this paper is consistent with the U.S. regulations for research with human subjects. U.S. Department of Health and Human Services, National Institutes of Health, and Office for Human Research Protections, The Common Rule, Title 45 (Public Welfare), Code of Federal Regulations, Part 46 (Protection of Human Subjects) (Washington D. C.: DHHS, revised January 15, 2009; effective July 14, 2009). These regulations do not require understanding of all the information disclosed, but stipulate that a researcher may only seek consent "under circumstances that provide the prospective subject or the representative sufficient opportunity to consider whether or not to participate and that minimize the possibility of coercion or undue influence" Title 45 , Section 46.116 . 
the content of the disclosure requirement may be derived by examining how the manipulation of information by the recipient of consent can give her illegitimate control over the consent decision. The conclusions we draw in this paper therefore apply mutatis mutandis to other contexts in which consent is obtained.

Our argument here is guided by two constraints on any plausible account of consent. First, the account must make valid consent possible. Second, if the account claims that some factor is a necessary condition for valid consent, it should also explain why lacking that factor invalidates consent. When there is no such explanation available, we take that as evidence that the factor is not a necessary condition for valid consent.

\section{Consent and Fraudulent Disclosure}

When I grant someone consent I exercise a right in a way that permits her to do something that would otherwise be impermissible. Take the right to bodily integrity, for instance. This right imposes a duty on others not to trespass on the right holder's body. Suppose your doctor notices an abnormal looking mole on your neck that she judges to be an early stage skin cancer. If, without asking you, she applies liquid nitrogen to a cotton swab and presses it against the affected tissue, then she violates your right because she trespasses on your body-by performing cryosurgery on you - without your permission. For competent agents the right to bodily integrity is an autonomy right that includes the power to waive the duty against trespass. If your doctor tells you that in her professional opinion the mole on your neck is an early stage skin cancer which could be removed by applying liquid nitrogen, and explains the procedure to you, then you can authorize her to do it, and no rights violation will result.

In consenting to medical research participation, a prospective participant exercises one or more autonomy rights, thereby giving the researcher (or other clinical staff) permission to perform acts that would otherwise violate his rights. Consequently, perhaps the simplest way to ascertain what is required for valid consent to research participation is to consider the ways in which the exercise of autonomy rights can fail. Two have been widely discussed in the research ethics literature: incapacity ${ }^{13}$ and

${ }^{13}$ Incapacity invalidates consent because autonomy rights can only be exercised by someone who has certain abilities, including the ability to make decisions on the basis of reasons. For example, someone suffering from dementia may not be able to remember the information she has been told about the risks and benefits of a medical procedure and so 
coercion. ${ }^{14}$ However, the way in which fraud can invalidate consent has received little attention from bioethicists. ${ }^{15}$

Consider the following two examples of a consent process in which a researcher requests the consent of an individual for participation in a clinical trial designed to test a drug that has risks A, B, C, and D. ${ }^{16}$

In the first case, the researcher only knows that the drug has risks $\mathrm{A}$ and B. She does not know about risk C or D. At this time, no one knows about these risks, so the researcher is not negligently ignorant. During the consent process, she discloses that the drug has risks $\mathrm{A}$ and $\mathrm{B}$ and that there may be unknown risks. The prospective participant fully understands the disclosed information and agrees to ingest the drug. This appears to be a straightforward case of valid consent.

In the second case, the researcher knows that the drug has risks A, B, and $\mathrm{C}$ but she does not know about D. Again, she is not negligently ignorant. During the consent process, she discloses that the drug has risks A and B and that there may be unknown risks; but she does not disclose risk $\mathrm{C}$. The prospective participant fully understands the disclosed information and agrees to ingest the drug. This appears to be a case of invalid consent.

What explains the normative difference? It cannot be incapacity because both participants are competent. It cannot be coercion because in neither

may be incapable of making an informed decision about whether to undergo it. For more on incapacity, see Joel Feinberg, Harm to Self. (New York: Oxford University Press, 1984), esp. chap. 26; James Drane, "The many faces of competency," Hastings Center Report 15 (1985): 17-21; Alan Buchanan and Dan W. Brock, "Deciding for Others," Milbank Quarterly 64 (1986): 17-94; and Alan Wertheimer, Consent to Sexual Relations (Cambridge University Press, 2003), esp. chap. 10.

14 Coercion invalidates consent by undermining voluntariness. For example, if a physician were to refuse to treat her patient unless he enrolled in a research study, this would undermine the voluntariness of his consent to research participation. For more on coercion, see Robert Nozick, Anarchy, State and Utopia (Oxford: Blackwell, 1974), 262-5; Feinberg, Harm to Self, esp. chap. 23 and 24; Alan Wertheimer, Coercion (Princeton, N.J.: Princeton University Press, 1987); and Jennifer S. Hawkins and Ezekiel. J. Emanuel, "Clarifying Confusions about Coercion," Hastings Center Report 35 (2005): 16-9.

15 Feinberg, Harm to Self, 285-300 is a notable exception on whom we draw in this paper. Also see Alan Wertheimer, Exploitation (Princeton: Princeton University Press), 254-257. The way in which fraud can invalidate consent has been addressed at length in other contexts, such as contract law. As Duncan Kennedy points out, "...the exceptions to the enforcement of agreements made for cases of fraud, duress, and incapacity are constitutive of the model of free contract." Duncan Kennedy, "Distributive and Paternalist Motives in Contract and Tort Law, with Special Reference to Compulsory Terms and Unequal Bargaining Power," 41 Maryland Law Review 563 (1982): 577. As noted in footnote 8, Gert, Culver, and Clouser (1997) have argued that the purpose of disclosure is the avoidance of deception.

16 For purposes of illustration, we focus on the explanation of the risks and assume that all other ethically required aspects of the consent process are carried out. 
case is the participant threatened. It cannot be a failure of understanding because both participants understand the same information-that the drug has risks $\mathrm{A}$ and $\mathrm{B}$. It cannot be that not all of the true propositions about the drug are disclosed to the participants—risk D is not disclosed in either case (because neither researcher knows about it). The only difference is the discrepancy between what the researcher knows and what she discloses. In the first case the researcher discloses all the risks she knows about, but in the second case she withholds something that she knowsnamely, that the drug has risk $\mathrm{C}$.

In cases like these, the researcher's failure to disclose certain facts makes a normative difference because of its effect on the autonomy of the person tokening consent. To claim that morally competent adults have autonomy rights, like the right to bodily integrity, is to claim that they have rights to control certain aspects of their lives. ${ }^{17}$ If another agent usurps that control, then she violates that right. For example, if a thief credibly threatens to stab you unless you hand over your wallet, then the thief, not you, is the person in control of your life with respect to the act of handing over your money. Coercion here undermines the voluntariness of your action. But coercion is not the only way in which a person's autonomy can be violated. If someone manipulates or deceives you, then your role as agent has also been usurped: the manipulator or deceiver controls what you do. In general, if agent A controls agent B's decisions about something over which agent $\mathrm{B}$ has an autonomy right without B's permission, A undermines the voluntariness of B's decisions. When the researcher withholds information about a risk that she reasonably believes would be relevant to the prospective participant's enrolment decision, she arrogates his role as agent by determining what information he gets to consider. Her manipulation of the information he receives usurps his agency and thereby undermines the voluntariness of his decision. This is why the token of consent is invalid in the second case but not in the first.

Withholding information gives someone control over another's decision only when that information is relevant to the decision being made. Following Joel Feinberg, we call this set of information the "inducement

\footnotetext{
17 Note that this claim does not beg the question in favor of a will theory of rights (as compared to an interests theory). Either type of theory can endorse the claim that some of our rights protect choices. It is just that proponents of an interests theory will ultimately justify the protection of those choices through its positive effect on the interests of autonomous people. Compare Gopal Sreenivasan, "A Hybrid Theory of Claim Rights," Oxford Journal of Legal Studies 25 (2005): 261-2; and D.N. MacCormick, "Rights in Legislation," in P. Hacker and J. Raz eds., Law, Morality, and Society (Oxford: Clarendon Press, 1977): 207-8.
} 
set."18 In the case of consent to research participation it is composed of those propositions that would dispose the potential participant one way or another with respect to enrollment. However, the content of the inducement set is not identical to the content of the disclosure requirement because the researcher is generally not in a position to know exactly which propositions would decide a potential participant's enrollment decision. Instead, the content of the disclosure requirement is given by those propositions that it is reasonable for the researcher to expect to be dispositive for this participant. ${ }^{19}$ We call the kind of disclosure that withholds or misrepresents these propositions fraudulent disclosure. Fraudulent disclosure occurs when:

(1) R asks P to exercise an autonomy right in order to render a proposed act or acts permissible that would otherwise be impermissible; and

(2) When describing the proposed act(s) R voluntarily withholds or misrepresents some proposition that $\mathrm{R}$ knows, and that $\mathrm{R}$ has reason to believe is in P's inducement set.

On this account, ill intent on the part of $\mathrm{R}$ is not a necessary condition of fraudulent disclosure. If $\mathrm{R}$ voluntarily fails to reveal some salient fact, when attempting to obtain consent, then $\mathrm{R}$ commits fraudulent disclosure by exercising illegitimate control over P's decision even if her aim is benign. Indeed, R need not even be withholding the information in order to get P's consent. $\mathrm{R}$ will undermine voluntariness if she simply knows the fact, has reason to believe that it is relevant to P's decision, and does not disclose it. Since the legal concept of fraud is ordinarily understood to require fraudulent intent, the concept of fraudulent disclosure is quite different and will apply to a wider range of cases. The legal concept of fraud and the ethical concept of fraudulent disclosure should therefore not be equated.

We expect that the majority of cases of fraudulent disclosure that occur in clinical research are non-malevolent. For example, the Jewish Chronic Disease Hospital case is a paradigmatic example of non-malevolent fraudulent disclosure. The researchers acted under the false assumption that it would be better for their patients not to be told the precise nature of the

\footnotetext{
18 According to Feinberg, it comprises "all the true propositions which, if a given subject believed them, would be part of his inducement for or against a given act or decision," Feinberg, Harm to Self, 307 .

19 In general, this will comprise those facts that prospective participants frequently find relevant to their decisions (what we might call a "usual person" standard), along with any facts that the investigator has reason to think are in the inducement set of the particular person she is enrolling.
} 
foreign cells. ${ }^{20}$ The fact that the researchers were concerned about the patients' reactions to the word "cancer" suggests that they thought disclosing this information might dispose a patient to refuse the experimental procedure, which is evidence that this is exactly the sort of information that ought to have been disclosed.

The foregoing analysis shows why not disclosing certain propositions invalidates consent to research participation in cases like the Jewish Chronic Disease Hospital case. When a researcher withholds or misrepresents information that she reasonably believes is relevant to an enrollment decision, she commits fraud, which renders consent involuntary. Our analysis therefore implies that the regulations and guidelines are correct that a lot of information should usually be disclosed to prospective participants, since there are many facts that researchers can reasonably expect to be in participants' inducement sets. However, the analysis does not imply that prospective participants must understand all of this information in order to give valid consent. Understanding is a separate criterion for consent, and thus it remains a separate question what must be understood in order for consent to medical research participation to be valid.

\section{Two Objections}

Before proceeding further, it is worth considering two possible objections to our account of fraudulent disclosure. First, one might argue that fraudulent disclosure, as we have defined it, does not always undermine voluntariness so much that it invalidates consent. Control and voluntariness come in degrees. As the degree to which another controls an agent's act increases, the degree to which her act should be considered voluntary decreases. For example, a thief who credibly threatens to kill his victim controls her more than one who merely threatens to tweak her nose, and her decision to hand over her money seems much less voluntary in the former case than the latter. This suggests that sometimes an act of consent can

20 In the clinical care setting, it is sometimes argued that doctors may be permitted to withhold information that they would otherwise be required to disclose if they have good reason to believe that that information would severely and adversely affect their patient. A doctor's obligation to not harm her patient is what purportedly justifies this privilege to withhold relevant information. But this justification would not apply to the Jewish Chronic Disease Hospital case because the injection of cancer cells was not in the patient participants' clinical interests. 
be controlled to some degree, while still being sufficiently voluntary that it is morally transformative. ${ }^{21}$

The question of how much control is sufficient to render a token of consent invalid is interesting, but it is a question that we deliberately set aside. An answer to this question is no more pressing for the analysis of fraud than for the analysis of other ways in which one agent can invalidate another's consent, such as coercion or manipulation. Whatever the right account of the degree of control that renders an act sufficiently involuntary so as to cross the line between valid and invalid consent, it is one that can be incorporated into our analysis. It is also worth noting that whether or not a particular act of fraudulent disclosure invalidates consent does not affect whether researchers act wrongly when engaged in fraudulent disclosure. It is wrong to control another's decision without authorization because it fails to respect autonomy and this is true irrespective of the degree of control. ${ }^{22}$

Second, it is possible that a prospective participant's inducement set could include propositions that we do not intuitively judge that he has the liberty to receive. For example, suppose that a potential participant tells the researcher that ever since his partner's infidelity he has vowed not to support the projects of adulterers and he asks the researcher whether she or her co-investigator have ever been unfaithful to their partners. ${ }^{23}$ The researcher then has good reason to believe that true propositions about her and her co-investigator's fidelity are in the participant's inducement set. According to our account the researcher therefore has an obligation to disclose these propositions, if she knows them, or risk invalidating the person's consent. But, surely, not only is the researcher not obliged to disclose whether she has been unfaithful to her partner, she has a duty not to disclose what she knows about her co-investigator's private life. Cases like this therefore present apparent counterexamples to our view.

The objection is correct that sometimes there is information which is in a prospective participant's inducement set, but which may or should be withheld. However, this does not show that our account is false, it just

${ }^{21}$ Faden and Beauchamp in A History and Theory of Informed Consent (New York: Oxford University Press, 1986), argue that valid consent must be "substantially autonomous," ibid., 237-241, which in turn requires that the act of consenting must be "substantially noncontrolled" ibid., 256-262.

22 Compare Shelly Kagan, Normative Ethics (Boulder: Colorado. Westview Press 1998), 106-16.

23 Compare T.M. Williamson, "Research, Informed Consent, and the Limits of Disclosure," Bioethics 15 (2001): 341-363. 
shows that there can be unusual cases in which additional moral factors must be incorporated into the ethical analysis and which therefore make it more complicated. Researchers have a pro tanto duty to disclose those propositions that they have reason to believe are in the participant's inducement set. However, other moral factors can give them reasons not to disclose some of these same propositions. These reasons may be sufficient to outweigh the pro tanto duty to disclose. For example, people have privacy rights over certain information, which permit them to withhold this information even when they would otherwise be obliged to disclose it. Facts about one's marriage and facts about another's marriage that were given in confidence fall into this category. In such cases, the researcher may obtain consent without disclosing some of the propositions that she has reason to think are in the prospective participant's inducement set. However, even in these cases, she must avoid withholding the information in a way that inappropriately influences the prospective participant's decision about enrollment. She must, therefore, clearly disclose that the information is being withheld because the potential participant does not have a liberty to receive it. It is then up to the potential participant to decide whether an intelligent enrollment decision can be made in the absence of that information. ${ }^{24}$

In the next section we distinguish a distinct duty that bears on the disclosure component of the consent process: the researcher's professional duty to know. In Sections V and VI we consider whether there are alternative explanations of the disclosure requirement that would require participants to understand all the information that should be disclosed to them; we argue that there are not. We then return, in Section VII, to the content of the duty to disclose, which we derive from more detailed consideration of the ways in which it is possible to commit fraudulent disclosure.

24 The researcher's pro tanto duty to disclose explains why the following apparently similar case is ethically problematic. Imagine that a researcher learns that she could earn a lot of money if she were to sign a contract not to disclose the risks of an experimental drug. She decides to sign the contract, but she is upfront with prospective participants. She says, "I have promised not to tell you about the risks of the drug being tested, and so I will not be disclosing that information to you. You have to decide whether an intelligent enrollment decision can be made in the absence of that information." In this case the researcher was not permitted to sign the contract that caused her to acquire this duty. Signing the contract violated her existing duty to disclose all those propositions believed to be part of the participant's inducement set. Our thanks go to Sergio Tenenbaum for suggesting this case. 


\section{Disclosure and Professional Duties to Know}

Consider a variant on the two cases presented in Section II. In this case, the researcher knows that the experimental drug has risks $\mathrm{A}, \mathrm{B}$, and $\mathrm{C}$, but she does not know about D. However, the occurrence of $\mathrm{D}$ has been widely reported in the medical literature, and most other medical professionals working in the researcher's specialty do know about $\mathrm{D}$. The researcher only discloses that the drug has risks $\mathrm{A}, \mathrm{B}$, and $\mathrm{C}$ and that there may be unknown risks. The prospective participant fully understands the information he has been given and agrees to ingest the drug.

Since the researcher fully discloses those propositions that she knows and has good reason to believe are in the prospective participant's inducement set, she has not engaged in fraudulent disclosure. However something does seem to have gone awry in the disclosure process: the researcher ought to have known about risk D and then informed the participant. This case therefore shows that medical researchers have at least two duties that bear on the disclosure component of consent. The first is a duty to disclose. We have argued that this is best understood as a duty to avoid illegitimately controlling another person, and the violation of this duty risks invalidating consent. The second is a professional duty to know certain facts. The knowledge base for medicine and clinical research is evolving, and so properly discharging this professional duty involves more than merely acquiring the necessary qualifications for professional practice; it also requires an ongoing commitment to acquiring relevant knowledge about one's field of expertise. $^{25}$

Thus, in this third case, the researcher does not know about a risk that other medical professionals working with the drug usually know, and so she has failed to fulfill her professional duty to know. However, the researcher does disclose all the facts that she knows and has reason to believe are in the prospective participant's inducement set, and so she does appropriately discharge her duty to disclose. The researcher does not exercise any illegitimate control over the prospective participant-in failing to know about risk $\mathrm{D}$, she gains no control over the prospective participant's

25 According to the Declaration of Helsinki's basic principles for all medical research:

Medical research involving human subjects must conform to generally accepted scientific principles, be based on a thorough knowledge of the scientific literature, other relevant sources of information, and on adequate laboratory and, where appropriate, animal experimentation. (WMA, Helsinki, B2).

See, also, CIOMS, International Ethical Guidelines, Guideline 1. 
decision - which explains why her failure to know is not properly categorized as a form of fraudulent disclosure. A wrong has been done to the participant; but it is not the wrong of overriding his autonomy. His consent may therefore still be valid, if the other conditions for valid consent are met, despite the clinical incompetence of the researcher. ${ }^{26}$

\section{The Understanding Requirement}

According to the standard view, the purpose of disclosure is the achievement of understanding. Consequently, on that view, the content of the understanding requirement is identical to the content of the disclosure requirement, that is, in order to give valid consent participants need to understand everything that ought to be disclosed to them. However, in Section II we argued that researchers have a duty to disclose certain information to prospective participants during the consent process because they otherwise risk invalidating their participants' consent by committing a form of fraud. Researchers can avoid fraudulent disclosure without their participants understanding all the information that should be disclosed to them. Hence, if the avoidance of fraudulent disclosure is the only justification of the disclosure requirement, then participants can give valid consent without understanding all the information that should be disclosed to them. However, the analysis so far leaves open the possibility that there is a further justification for the disclosure requirement that does entail that everything that should be disclosed must also be understood. We now attempt to identify such an argument in the existing accounts of the understanding requirements, and argue that any such argument will fail. The disclosure and understanding requirements are therefore conceptually distinct and so (plausibly) have different contents.

There are two accounts of the understanding requirement that might imply that the content of the understanding requirement includes all the propositions that we have argued ought to be disclosed: the inducements view and the interests view. According to the inducements view, in order to give valid consent a prospective participant needs to understand

26 There is, of course, an important difference between negligent ignorance and willful ignorance. When a researcher chooses not to learn some proposition that she knows or has reason to believe is in the prospective participant's inducement set, then she does exercise illegitimate control, and she therefore neglects both her professional duty to know and her duty to disclose. 
everything that the researcher knows and has reason to think is in his inducement set. Since we have argued for an inducements view of disclosure, clearly an inducements view of understanding would require patients to understand everything that ought to be disclosed. Ruth Faden and Tom Beauchamp advance a version of the inducements view of understanding. ${ }^{27}$ According to the interests view, proposed by David Wendler and Christine Grady, in order to give valid consent to medical research participation a prospective participant needs to understand all those true propositions about the research that are relevant to his or her interests. ${ }^{28}$ It might be argued that, in general, those propositions that are relevant to someone's enrollment decision (and so in his inducement set) are also propositions relevant to his interests, and so that the content of the understanding requirement includes the content of the disclosure requirement. There is a range of conceptions of interests, so there could be a corresponding range of versions of the interests view, each with variations on the information that would have to be disclosed and understood. ${ }^{29}$ We do not need to adjudicate between them because the criticism we make below will apply whatever the conception of interests adopted. In the following section we assess the inducements and interests views together. ${ }^{30}$

\section{A Dilemma}

Following the second constraint stated at the beginning of this paper, if either the inducements or interests view were the correct account of the understanding requirement, it should explain why a failure to understand

27 Faden and Beauchamp supplement their inducements view with a requirement that there be shared understanding between the researcher and the participant about what is being authorized. See Faden and Beauchamp, A History and Theory of Informed Consent, 298-336. We do not address this supplementation here, since our criticism applies to the inducements view and to views that include the inducements view in addition to other content.

28 David Wendler and Christine Grady "What Should Research Participants Understand to Understand They Are Participants in Research?” Bioethics 22 (208): 203-8, 205-6.

29 Roger Crisp, "Well-Being," The Stanford Encyclopedia of Philosophy (Winter 2008 Edition), Edward N. Zalta ed.,http://plato.stanford.edu/archives/win20o8/entries/well -being/; L.W. Sumner, Welfare, Happiness, and Ethics (Oxford: Clarendon Press, 1999).

30 On a purely subjective account of interests, the content of one's inducement set might be identical to the set of propositions relevant to one's interests. Thus we could consider the inducements view to be a variant of the interests view. For clarity, in what follows we keep them distinct, since most people think that there is at least some objective component to interests. 
relevant information renders a token of consent invalid. Here a proponent of either view faces a dilemma.

What might explain why understanding everything about a research study that is in one's inducement set or relevant to one's interests is necessary for valid consent? A natural explanation would run as follows. It is impossible to give valid consent to something unless you know what you are consenting to. However, in order to know what you are consenting to, you must know all those facts that are relevant to your decision about whether to give consent. In the case of research, this would mean knowing everything about the proposed study that is relevant to making a decision about being enrolled in it. On the inducements view, it consists of those true propositions that might make a difference to a prospective participant's choice if he believed them; on the interests view, the relevant information consists of those true propositions relevant to a prospective participant's interests.

This explanation would make sense of why a lack of understanding might invalidate consent. However, it would also render consent impossible. No one is ever in a position to know all the true propositions about medical research that are either relevant to a participant's interests or in a participant's inducement set. Medical research ventures into the unknown, which means that researchers cannot know the truth-value of every salient proposition. For example, a researcher studying the efficacy of a novel chemical compound for the treatment of tuberculosis will not know whether the drug being tested will cure someone of the disease (assuming she has an honest null hypothesis).

In order to escape this implication, proponents of the inducements and interests views could re-formulate their accounts. They could argue that since a duty to disclose must be constrained by what it is possible for the researcher to disclose, their respective accounts of the understanding requirement must be similarly restricted. The restricted views would say that prospective participants need to understand all those propositions about the research known to the researcher that are relevant to their interests or in their inducement set. This restriction renders the views more plausible-in that the researcher's obligation is now one that she can discharge.

However, such a restriction leads to the other horn of the dilemma: it fails to satisfy the second constraint on an account of consent by failing to explain why a lack of understanding renders consent invalid. We proposed an explanation of why a participant might need to understand everything in his inducement set or relevant to his interests in order to give valid 
consent by supposing that this might be necessary in order for him to understand what he is consenting to. But this explanation makes no sense on the restricted view. Reformulated in the terms of the restricted view, it would say that in order to know what he is consenting to, a participant needs to know everything that the researcher knows about the research that is relevant to his interests or in his inducement set. But whether a participant knows what he is consenting to surely depends only on facts about his mental states and facts about what he is actually consenting to. It is hard to see how the state of knowledge of the researcher could make a difference to whether the participant knows what he is consenting to.

Intuitively, what the researcher knows should make a difference to the validity of a prospective participant's token of consent. However, this intuition must not only be entailed by, but also explained by any plausible account of consent. If an ethical theory merely entails a particular judgment, without explaining it, the theory risks being ad hoc. The intuition is entailed by the restricted versions of the inducements and interests views, which gives them a veneer of plausibility as accounts of consent. However, neither view can explain why a difference between what the researcher knows about the research and what the participant knows can make a difference to the validity of the participant's consent. Our account of the disclosure requirement, on the other hand, both entails and explains the intuition: when a researcher does not disclose a proposition that she knows and has good reason to believe is in a prospective participant's inducement set, then she exercises illegitimate control over his enrollment decision. No mention of participant understanding is necessary for this explanation.

It might seem that we have only considered one possible answer to the question posed, and that other accounts of consent might be able to explain why everything that ought to be disclosed must also be understood. For example, on Faden and Beauchamp's view, a researcher only has genuine authority to enroll a potential participant into a research study if the enrollment decision is substantially autonomous. One might think that understanding everything that ought to be disclosed is a necessary condition for such autonomous authorization. But such an explanation prompts the same question as before: what explains why what must be understood for the authorization to qualify as substantially autonomous is identical to what ought to be disclosed? No doubt some understanding of what is involved in the research is necessary for authorization to qualify as substantially autonomous, and disclosure is one way in which someone could acquire that understanding. But considerations like these cannot 
explain why the content of what needs to be understood necessarily tracks the content of what ought to be disclosed..$^{31}$ No account of consent that we know of has an understanding requirement that explains why its content is necessarily identical to the disclosure requirement, and the best explanation that we could construct faces a problematic dilemma.

Neither the inducements nor the interests views give the correct account of the understanding requirement, since neither can explain how a failure of understanding invalidates consent while still allowing that consent is possible. The content of the understanding requirement is therefore not identical to the content of the disclosure requirement. Two significant implications follow.

First, the correct account of the understanding requirement is likely to call for less to be understood about research than most commentators assume. Though we agree that at least something must be known about the act consented to, we see no reason to believe that as much needs to be understood as the interests and inducements views would imply. Determining exactly what needs to be understood in order to give valid consent to medical research participation is a topic for another paper. Since we have argued that an inducements account of the disclosure requirement is correct, the correct account of the understanding requirement is likely to lie between the view that nothing must be understood and the extensive requirements of the interests and inducements views.

Second, if the inducements view of understanding is false, then it is possible to give valid consent to research participation without understanding everything that ought to be disclosed. The data we cited on comprehension suggests that many otherwise capable participants do not understand key elements of the information disclosed to them about the research. If they had to understand all this information in order for their consent to be valid, then we would have to conclude that many otherwise ethical medical trials are unethical. However, since our analysis revealed no reason to think that prospective participants must understand all the information that is disclosed to them, we need not yet accept this conclusion.

\footnotetext{
${ }^{31}$ Note that the justification we have given for the disclosure requirement is consistent with a conception of consent as autonomous authorization. According to our account, a substantially autonomous decision will require both that the disclosure process is nonfraudulent and that the person granting consent has the requisite level of understanding about the decision she is making. However, these two requirements are not conceptually tied in the way that the standard view supposes.
} 


\section{Appropriate Disclosure}

We already know the propositional content of what a researcher ought to disclose: all those propositions about the research that she knows and has reason to think are in the prospective participant's inducement set. Voluntarily withholding or misrepresenting this information involves exercising illegitimate control over an enrollment decision. However, it is possible for a researcher to disclose all of this information to a prospective participant, but to do so in a way that still invalidates his consent. For example, if the researcher were to explain key elements of a study in English to a potential participant whom she knew spoke only Spanish, we would consider his tokening of consent as invalid as if she had withheld those elements altogether.

This example shows that it is not necessary for a researcher to literally withhold relevant information in order to commit fraudulent disclosure: it is sufficient to provide the information in a way that she knows (or should know) that the prospective participant is likely to be unable to understand. The explanation of why consent is invalid when a researcher fails to provide information in a way that she can reasonably expect a prospective participant to understand is the same as the explanation for why consent is invalid when a researcher withholds relevant information: the person asking for consent thereby has illegitimate control over whether the other person gives it, and this renders the resultant token of consent insufficiently voluntary.

Disclosing relevant information in a different language is an extreme case. The following example illustrates a more common way in which researchers may provide all the information to participants that they ought to, but still engage in fraudulent disclosure.

Jargon. Tiffani has had Parkinson's disease for several years. While she remains well enough, she wants to help other sufferers, but she is very cautious about worsening her own symptoms. She is considering participating in a study investigating the mechanisms underlying chronic autonomic failure. The principal investigator is very enthusiastic, and explains the study in Tiffani's native English, but Tiffani doesn't understand half of what he says. At one point he tells her that she'll be given a drug called "phenylephrine" to see if she has "abnormal reflexive heart rate responses." Phenylephrine is usually "well tolerated" in "healthies" but she should be aware that it may cause "decreases in her pulse rate or blockade of transmission of certain electrical impulses in the heart." Is this study safe for her, Tiffani wonders?

We take it that most people would agree that if Tiffani signed a consent form right now, her consent would be invalid. Our account explains why: 
the researcher has good reason to believe that Tiffani will be unable to understand some of the facts he knows are relevant to her enrollment decision. ${ }^{32}$

Considering examples like Jargon allows us to derive some commonsense conditions on how researchers should disclose information so as to avoid fraud. They include that the researcher should disclose the relevant information in a clear manner, in a language the prospective participant speaks, and that the consent form should be written at a low enough reading level. ${ }^{33}$ The researcher should also give the participant an opportunity to ask questions in case there is information that is part of his inducement set that she has not disclosed or not disclosed clearly enough. Conditions like these state what is needed for appropriate disclosure.

Our account also has some less obvious implications about what constitutes appropriate disclosure. For instance, it shows the moral relevance of data about what people are likely to understand.

Ignoring the data. Dr Singh just returned to her clinical practice from a very interesting conference. At the conference she heard the term "therapeutic misconception" for the first time and saw a presentation of the data on how widespread it is. Dr Singh sees patients, but she also conducts some research and refers patients to colleagues' studies. The data suggests that her patients are therefore at high risk of having a therapeutic misconception regarding the

32 Compare the complaint of F.J. Ingelfinger 40 years ago who argued that " $[\mathrm{t}]$ he inconsiderate investigator, indeed, conceivably could exploit his authority and knowledge and extract "informed consent" by overwhelming the candidate-subject with information," F.J. Ingelfinger "Informed (But Uneducated) Consent" New England Journal of Medicine 287 (1972): 465-6, 466. The quotations used in Jargon are taken from a consent form used in a US academic medical center. Consent forms written at a level that many participants are unlikely to understand are the norm, rather than the exception. A study of the readability of the standard language provided by US medical school IRBs for use in consent forms found an average readability score of 10.6 on the Flesch-Kincaid grade scale. (A score of 10 means that the piece of writing is expected to be understandable for the average $10^{\text {th }}$ grade US student.) It is commonly estimated that around half of US adults read at an $8^{\text {th }}$ grade level or below. See Michael K. Paasche-Orlow, Holly A. Taylor, and Frederick L. Brancati, "Readability Standards for Informed Consent Forms as Compared with Actual Readability," New England Journal of Medicine 348(8) (2003): 721-726.

33 Compare the guidance offered in The Belmont Report:

The manner and context in which information is conveyed is as important as the information itself. For example, presenting information in a disorganized and rapid fashion, allowing too little time for consideration or curtailing opportunities for questioning, all may adversely affect a subject's ability to make an informed choice. Because the subject's ability to understand is a function of intelligence, rationality, maturity and language, it is necessary to adapt the presentation of the information to the subject's capacities. 
studies in which they are enrolled. Nevertheless, Dr Singh continues with her previous procedures for enrolling patients into research studies.

Ignoring the data shows the normative significance of the studies on participant understanding. The data on the prevalence of the therapeutic misconception has only become widely publicized within the medical community in the last 20 years. ${ }^{34}$ It may well have been a surprise for some clinical researchers to learn that competent adults are hobbled by systematic misconceptions, like confusing the fairly straightforward distinction between the aims of clinical research and clinical care. But this should no longer be a surprise. Today, many clinical researchers know (or should know) about the ways in which participants are likely to fail to understand the information that ought to be disclosed to them. ${ }^{35}$ Acquiring this information changes what a researcher knows about the cognitive processes of otherwise competent individuals, and thereby gives her a power over potential participants' decisions that she previously lacked. Consequently, this information should make a difference to the way in which researchers communicate with their potential participants. Failure to take this data

34 The term "therapeutic misconception," while first coined by Paul Appelbaum, Loren Roth, and Charles Lidz, "The Therapeutic Misconception: Informed Consent in Psychiatric Research," International Journal of Law and Psychiatry 5 (1982): 319-29, was not widely introduced until 1987, see Paul Appelbaum, Loren Roth, Charles Lidz, Paul Benson, and William Winslade, "False Hopes and Best Data: Consent to Research and the Therapeutic Misconception," Hastings Center Report 17 (1987): 20-24. For more details, see Jonathan Kimmelman, "The Therapeutic Misconception at 25: Treatment, Research, and Confusion," Hastings Center Report 37 (2007): 36-42; and Paul Appelbaum and Charles Lidz, "The Therapeutic Misconception," in E. Emanuel et al., eds, The Oxford Textbook of Clinical Research Ethics (New York: Oxford University Press, 2008). Studies on competent participants' understanding of key elements of research were not widely published until the early 1980s. For more details, see Flory et al., "Empirical Issues in Informed Consent for Research," 2008.

35 The last couple of decades have seen a flurry of studies and articles on patient and research participant understanding and decision-making. This research presents common forms of irrationality that otherwise competent individuals are subject to, in addition to outlining various ways in which physicians and researchers can present information to eradicate or lessen such irrational responses. See Amos Tversky and Daniel Kahneman, "The Framing of Decisions and the Psychology of Choice," Science 211 (1981): 453-458; Dan W. Brock and Steven Wartman, "When Competent Patients make Irrational Choices," in Brock's Life and Death (Cambridge University Press, 1990): 80-95; Donald Redelmeier, Paul Rozin, and Daniel Kahneman, "Understanding Patients' Decisions: Cognitive and Emotional Perspectives," JAMA 270 (1993): 72-76. Also see Gerd Gigerenzer and Reinhard Selten eds., Bounded Rationality: The Adaptive Toolbox (Cambridge, MA: MIT Press, 2001); Gerd Gigerenzer, Calculated Risks: How to Know When Numbers Deceive You, (New York: Simon \& Schuster, 2002); and Gerd Gigerenzer and Adrian Edwards, "Simple Tools for Understanding Risks: From Innumeracy to Insight," British Medical Journal. 327 (2003): 741-7. 
into account, and amend the consent process in light of it, amounts to a failure to properly discharge the duty to disclose.

We have mentioned a number of ways in which researchers may engage in fraudulent disclosure, even if they do not actively seek to deceive or manipulate their participants. However, is it always the case that if a researcher has reason to think that her participant doesn't understand some aspect of the required disclosure, then she risks fraud? We do not think so: sometimes a researcher can have reason to think that a prospective participant does not understand everything that she told him, but his token of consent is not thereby invalidated. Consider the following case.

Trusting Participant. Over the last decade, Gabriel has participated in half a dozen clinical trials at the Feelgood Medical Center. He enjoys helping other people and has built a great rapport with the physicians at the hospital, particularly the osteoarthritis specialist, Dr Chang. He is independent, well-educated, and now has a good understanding of what clinical research generally involves. Dr Chang recently contacted him about a new study examining the effectiveness of physical therapy for osteoarthritis that she thought he would be interested in. She gave him the consent form to read over and scheduled a discussion of the procedures involved, making sure that there would be plenty of time for questions. But when they meet he tells her: "I skimmed the first couple of paragraphs of the consent and then stopped reading. You can explain everything if you want, but I trust your judgment better than mine. If you think it's an okay study to be in, then I agree to be part of it. Let me just sign the form so we can get on with it."

Suppose that Dr Chang is as trustworthy as Gabriel believes, that she would like him to understand all the important aspects of the study, and is willing to put in the effort to make sure that he does. Moreover, Gabriel is perfectly capable of understanding the study. If Gabriel continues to show no interest in finding out the details, despite her efforts, would Dr Chang be doing something wrong in accepting his token of consent to enrollment? We think not. Dr Chang has given Gabriel a fair opportunity to understand those propositions that she knows and has reason to believe are in his inducement set. A fair opportunity consists in her willingness and ability to provide the required information in a way that she reasonably thinks could be understood by Gabriel, as well as her communication of that willingness. Dr Chang has done nothing that renders Gabriel less likely to understand some aspect of the study that is relevant to his enrollment decision. Thus, she does not commit fraudulent disclosure. Gabriel's consent may therefore be perfectly valid. ${ }^{36}$

${ }^{36}$ Whether or not Gabriel's consent is actually valid depends upon more than appropriate disclosure on the part of Dr Chang. It also requires that he had the necessary level of 
To fulfill the disclosure requirement a researcher must give a potential participant a fair opportunity to understand those aspects of the study that she knows about and reasonably believes are in the participant's inducement set. This fair opportunity is what appropriate disclosure consists in. But having a fair opportunity to understand is not sufficient for understanding. Once the potential participant is given this opportunity, it is up to him to engage with the information he has been given. A participant who does not want to find out as much as he could about a study does not thereby invalidate his consent to research participation, nor make it the case that the person requesting consent from him has failed in some duty. He simply makes it less likely that he will make the best decision he can.

This analysis of appropriate disclosure explains why the standard view's condemnation of Lazy Participant is premature. Whether or not Dawn gives valid consent to participation in Dr Abrams' study depends, in part, on the opportunities she had to understand the information that was disclosed to her. If Dr Abrams withheld some fact that it was reasonable to believe would be in Dawn's inducement set or if he disclosed all the relevant information in a way that was inattentive to the well-known misconceptions and cognitive biases that otherwise competent individuals have, then we would have reason to question the validity of Dawn's consent. But we already know that the consent form was written at an appropriate reading level for Dawn, and if Dr Abrams appropriately disclosed all those propositions that he knew and had reason to believe were in the inducement sets of his participants, then he discharged his duty of disclosure. The responsibility then falls to Dawn, and other participants like her, to take advantage of the opportunity that she has been given to make an intelligent enrollment decision. If Dawn does not take that opportunity, it does not follow that her token of consent is invalid; it is just that she may have made a poor decision.

A final caveat on the relationship between disclosure and understanding: we have not provided an account of the understanding requirement here; we have merely shown that there is no reason to believe that the content of the understanding requirement is as extensive as that of the disclosure requirement. Our analysis shows that the informational requirements for valid consent-disclosure and understanding-are conceptually

understanding and we have not given an account of the understanding requirement in this paper. We assume here that Gabriel has that level of understanding, whatever it turns out to be. And we assume that the reader, like us, finds it intuitively plausible that Gabriel's consent is valid in the case we describe and so that he understands enough of what he is agreeing to. 
distinct. This means that we can determine the content of the disclosure requirement independently of its relationship to the understanding requirement. Our analysis therefore implies that working out what needs to be understood in order for consent to be valid is a separate project. Since we accept that at least something must be understood in order for consent to be valid, there exists some lower bound on how little a potential participant can actually understand of what is disclosed to him. The precise location of that lower bound is a topic for another paper.

\section{Conclusion}

The regulations and guidelines that govern medical research are right to require that researchers disclose a great deal of information about their research to potential participants. However, the justification for this extensive disclosure requirement is the avoidance of a form of fraud, not the achievement of understanding. Though wholly ignorant consent would not be valid, contrary to a widely held assumption, potential research participants do not have to understand all the information they should be told.

Analysis of how fraud can be committed also allows us to derive the nature of the disclosure requirement. First, researchers have a duty to disclose the information that they know about the research that they have reason to believe is in a prospective participant's inducement set. Second, they have a duty to do so in a way that gives the prospective participant a fair opportunity to understand.

These implications for consent to research participation apply mutatis mutandis to other contexts in which consent is obtained. Whatever the context, the disclosure and understanding requirements have distinct justifications and so we should not expect them to have identical contents. And whatever the context, analyzing how the manipulation of information by the recipient of consent can give her illegitimate control over the consent decision will provide a way to derive what must be disclosed and how. ${ }^{37}$

\footnotetext{
37 For discussions and comments on earlier drafts of this paper, we thank Kirstin Borgerson, Gerald Dworkin, Michael Garnett, Bob Goodin, Frank Miller, Andrew Moore, Collin O'Neil, Annette Rid, Tait Szabo, Sergio Tenenbaum, Dave Wendler, and Alan Wertheimer. Earlier drafts were presented to audiences at the Clinical Center Department of Bioethics at the US National Institutes of Health, the Department of Philosophy at the University of Massachusetts, Boston, the 2010 Rocky Mountain Ethics Conference, and the 2011 Annual Meeting of the Society of Applied Philosophy. We thank the audiences at all four venues for their feedback. The ideas and opinions expressed are the authors' own. They do not represent any official position or policy of the National Institutes of Health, Public Health Service, or Department of Health and Human Services.
} 